\title{
Development of the External Genitalia of the Giant Prawn, Penaeus monodon*1
}

\author{
Hiroshi MotoH*2 and Prasit BuRI*2 \\ (Received September 10, 1979)
}

\begin{abstract}
The present paper deals with the morphological development of the external genitalia of Penaeus monodon FABRICIUS which will serve as a basis for future researches on the reproductive biology of this species.

Wild specimens were collected with fry lures, fish corrals, and trawlers, and cultured specimens from fishponds. The petasma length is taken as the median linear distance between the anterior and posterior margins of the organ, and the thelycum length the linear distance between the anterior edge of the boss-like antero-median plate and the posterior margin of the lateral plates.

A description is given of the metamorphosis of male and female genitalia of $P$. monodon. Specimens measuring about $11 \mathrm{~mm}$ in carapace length can be distinguished sexually by the rudimentary petasma in males or by the rudimentary median plate of the thelycum in females. When a male reaches about $34 \mathrm{~mm}$ in carapace length, the petasma almost assumes the character of the adult. The relationship between carapace length $(X)$ and petasma length $(Y)$ may be expressed as $Y=-3.5075+0.3025 X$. When a female reaches about $47 \mathrm{~mm}$ in carapace length, the thelycum assumes the character of the adult. The relationship between carapace length $(X)$ and thelycum length $(Y)$ may be expressed as $Y=-0.8147+0.1878 X$.
\end{abstract}

In the last quarter of this century, great progress in the artificial propagation of commercially important penaeid prawns has been achieved and various methods have been adopted in mass scale hatchery activities. However, shortage of spawners and high larval mortality constitute major problems. Thus, it has become necessary to understand the reproductive biology of the animal which until now is poorly known.

Regarding the description and/or observation of the development of external genitalia of penaeids, studies have been made on Penaeus merguiensis by TUMA," on $P$. indicus, Metapenaeus monoceros, $M$. dobsoni and Parapenaeopsis stylifera by GEORGe and RAO, ${ }^{21}$ on $P$. bubulus, $P$. latisulcatus, $P$. monodon, $P$. japonicus, $M$. affinis, M. joyneri, $M$. monoceros, Trachypenaeus curvirostris, Metapenaeopsis barbatus and $M$. acclivis by Kuво, ${ }^{31}$ on Parap. stylifera by TrRmizi, ${ }^{4 \prime}$ on $P$. japonicus by TrRmizI, ${ }^{5 \prime}$ and on Metapenaeus stebbingi by TIRMIZI and JAVED. ${ }^{6 !}$

However, so far as the present authors are aware, there is no detailed morphological study on the external genitalia of the giant tiger prawn, Penaeus monodon Fabricius.
The present paper deals with the description of the morphological development of the external genitalia of $P$. monodon.

\section{Materials and Methods}

Juvenile specimens of $P$. monodon were captured from the sea with the use of fry lures made of aquatic grasses and also from prawn cultivation ponds located on Panay Island, Philippines. Adult specimens were obtained from fish corrals at the mouth of Batan Bay and by trawling with $\mathrm{R} / \mathrm{V}$ SEAFDEC II off Iloilo, during the period of January 1977 to December 1978.

Morphometric measurements were patterned after that of TUMA ${ }^{11}$. The sizes of the prawns given in the present paper refer to carapace length (CL), defined as the linear distance between the post-orbital margin and the median posterior end of the carapace. Measurements were done with a slide caliper having an accuracy up to $0.1 \mathrm{~mm}$. The length of petasma (male genitalia) was measured as the median linear distance between the anterior and posterior margins of the organ (Fig. 3). The length of thelycum (female genitalia)

*1 Contribution No, 44 from the Aquaculture Dept. of SEAFDEC.

*2 Aquaculture Dept. of Southeast Asian Fisheries Development Center (SEAFDEC), P. O. Box. 256,

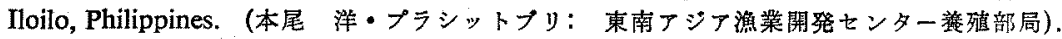


was measured along the median aperture as the linear distance between the anterior edge of the boss-like antero-median plate and the posterior margin of the lateral plates (Fig. 6). Thelycum width is the greatest distance between the two lateral plates.

\section{Results}

In the specimen as small as about $7 \mathrm{~mm}$ in carapace length (CL), the primitive endopod of the first pair of pleopod is only a minute tubular outgrowth located slightly below the base of the exopod, in addition, there are no appendix masculina and thelycum existing, thus the sexes cannot be distinguished. The primitive endopod has mostly a single seta at its tip portion (Fig. 1). Male specimens attaining about $11 \mathrm{~mm}$ in $\mathrm{CL}$ can be distinguished from females by the presence of the rudimentary appendix masculina (Figs. 2A \& C) and relatively narrower sternal space between the

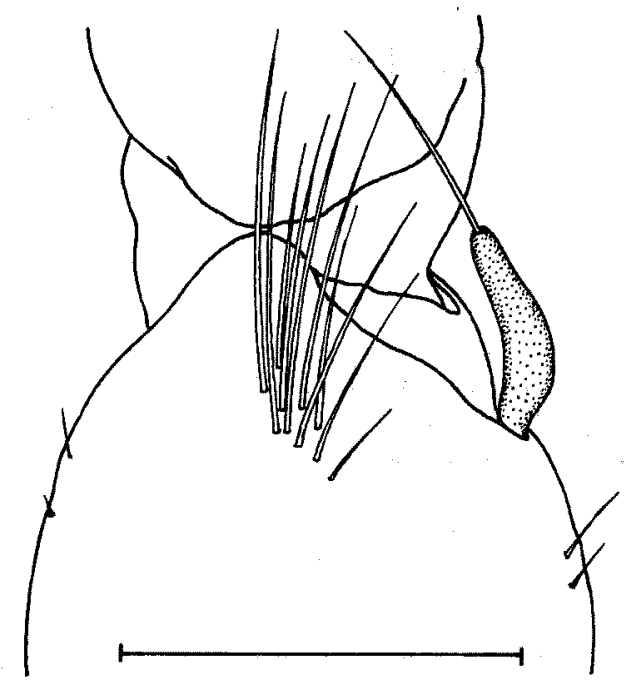

Fig. 1. Bud of endopod of the first pleopod $(7.2 \mathrm{~mm}$ in CL). Scale represents $0.5 \mathrm{~mm}$.
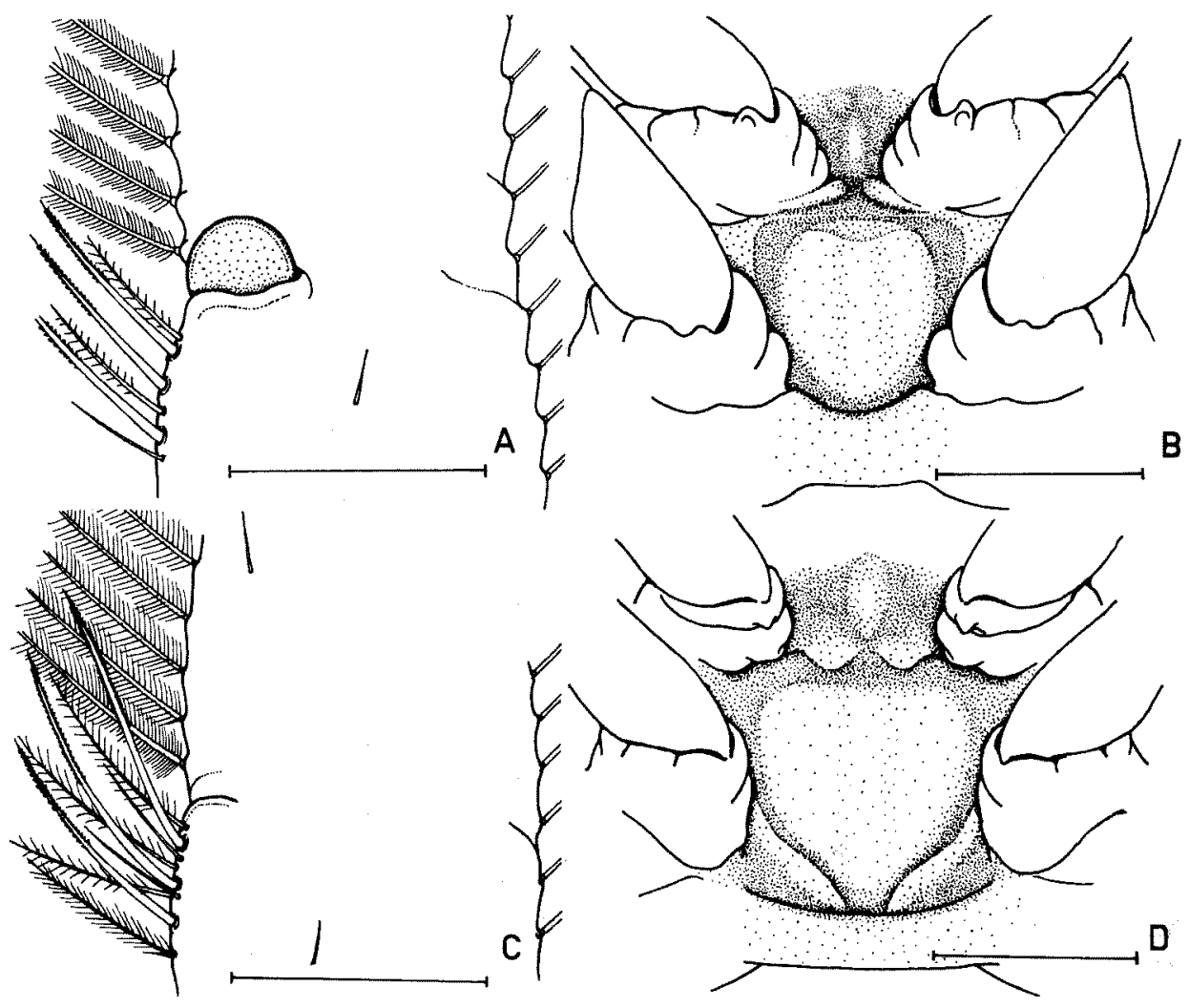

Fig. 1. Bud of appendix masculina (A) and narrower space between 4 th and 5 th pereiopods (B) in male (10.8 $\mathrm{mm}$ in $\mathrm{CL}$ ), and primitive tubercle on the 2 nd pleopod $(\mathrm{C})$, and thelycum (D) in female (11.3 $\mathrm{mm}$ in $\mathrm{CL}$ ). Scales for $A$ and $C$ represent $0.25 \mathrm{~mm}$, and for $B$ and $D, 1 \mathrm{~mm}$. 
bases of the fourth and the fifth pereiopod on each side than in the female. (Figs. 2B \& D).

\section{Development of the Petasma}

Specimens measuring about $11 \mathrm{~mm}$ in $\mathrm{CL}$ possess a small rudimentary petasma in the form of a knife-shaped projection situated at subapical portion of protopod (Fig. 3A). In the male specimens of about $22 \mathrm{~mm}$ in $\mathrm{CL}$, the petasma has grown almost twice of that in the previous stage in length, and is more or less triangular in shape with a broad proximal portion and narrow but rounded distal tip. A few minute hooks appeared along the inner border (Fig. 3B). When the male reaches about $24 \mathrm{~mm}$ in $\mathrm{CL}$, the triangular-shaped wing of the petasma has disappeared due to the formation of a slight fold indicating the formation of the median and the lateral lobes. The number of the minute hooks has increased. Now, more or less rectangular in profile, the petasma sits on a narrow stalk-like tubular portion (Fig. 3C). When the male reaches about $31 \mathrm{~mm}$ in $\mathrm{CL}$, the modified endopod already very much resembles the petasma of the adult. The inner margin is now lined with the numerous minute hooks, but at this stage both petasmal endopods of the first pair of pleopods are still rather small and do not meet along the midline but remain separated as two separate components. The tip of the ventral lobule is slightly folded inward forming a fishing hook and is relatively thickly calcified. The whole structure is very much like the petasma of $P$. indicus as described by GeORGE and RAO. ${ }^{21}$ A few (2-3) small bristles appear on the inner anterior marginal surface (Fig. 3D). When the prawn reaches about $34 \mathrm{~mm}$ in $\mathrm{CL}$, the petasma assumes almost the adult form. The two halves are now large enough so that their inner margins meet along the median line and are thus united together with the aid of the numerous minute hooks. However, the two components can be easily separated by physical force. The number of bristles increases on the inner surface of the lateral lobe. Both the median and the lateral lobes as well as the inwardly curved hooklike tips of the latter become more pronounced (Fig. 3E). As the animal attains $47 \mathrm{~mm}$ in $\mathrm{CL}$, the

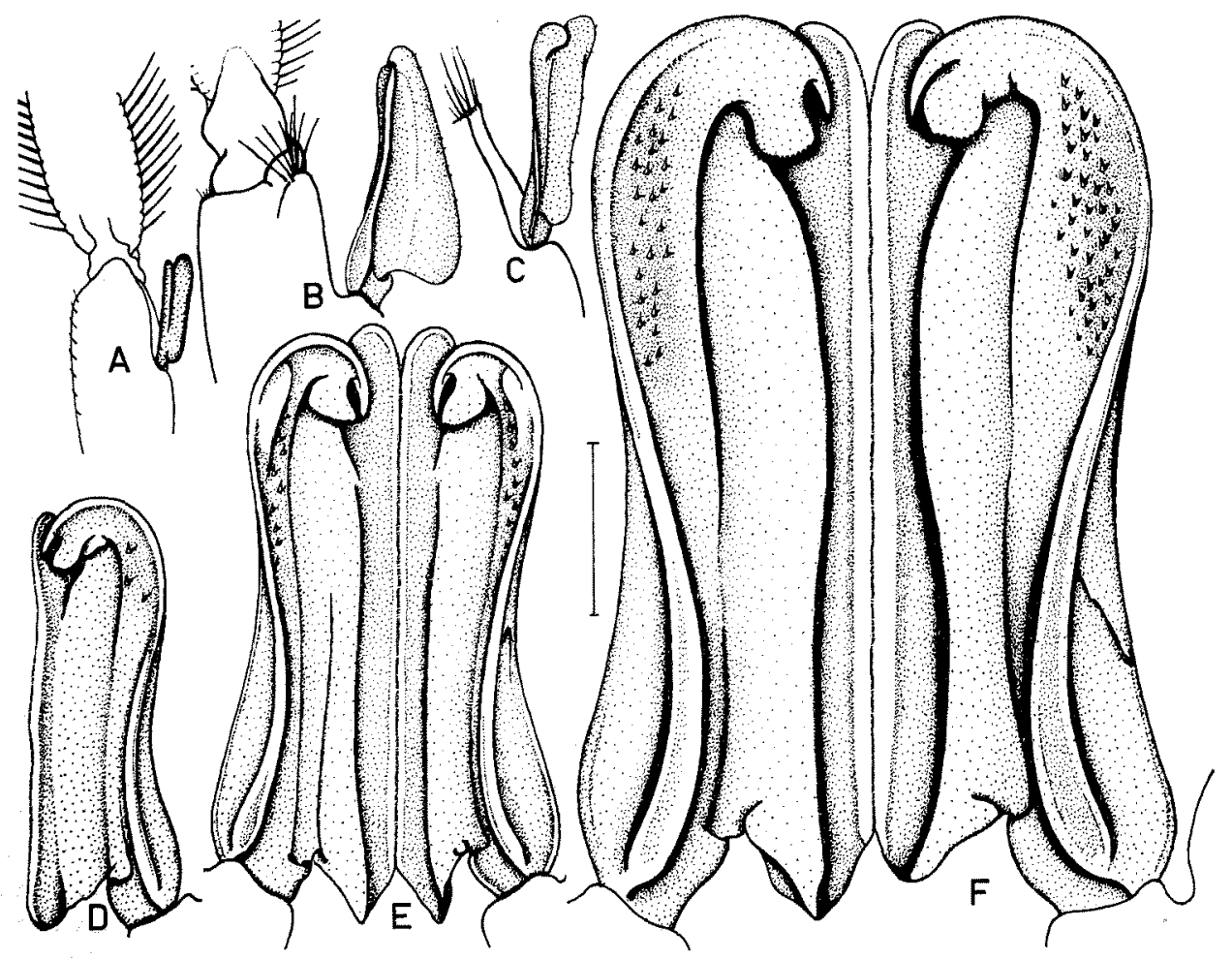

Fig. 3. Development of petasma. A, $11.2 \mathrm{~mm}$ in $\mathrm{CL} ; \mathrm{B}, 21.6 \mathrm{~mm}$ in $\mathrm{CL} ; \mathrm{C}, 23.5 \mathrm{~mm}$ in $\mathrm{CL}$; D, $26.9 \mathrm{~mm}$ in $\mathrm{CL} ; \mathrm{E}, 34.2 \mathrm{~mm}$ in $\mathrm{CL}$; and F, $46.8 \mathrm{~mm}$ in CL. Scale represents $2 \mathrm{~mm}$. 


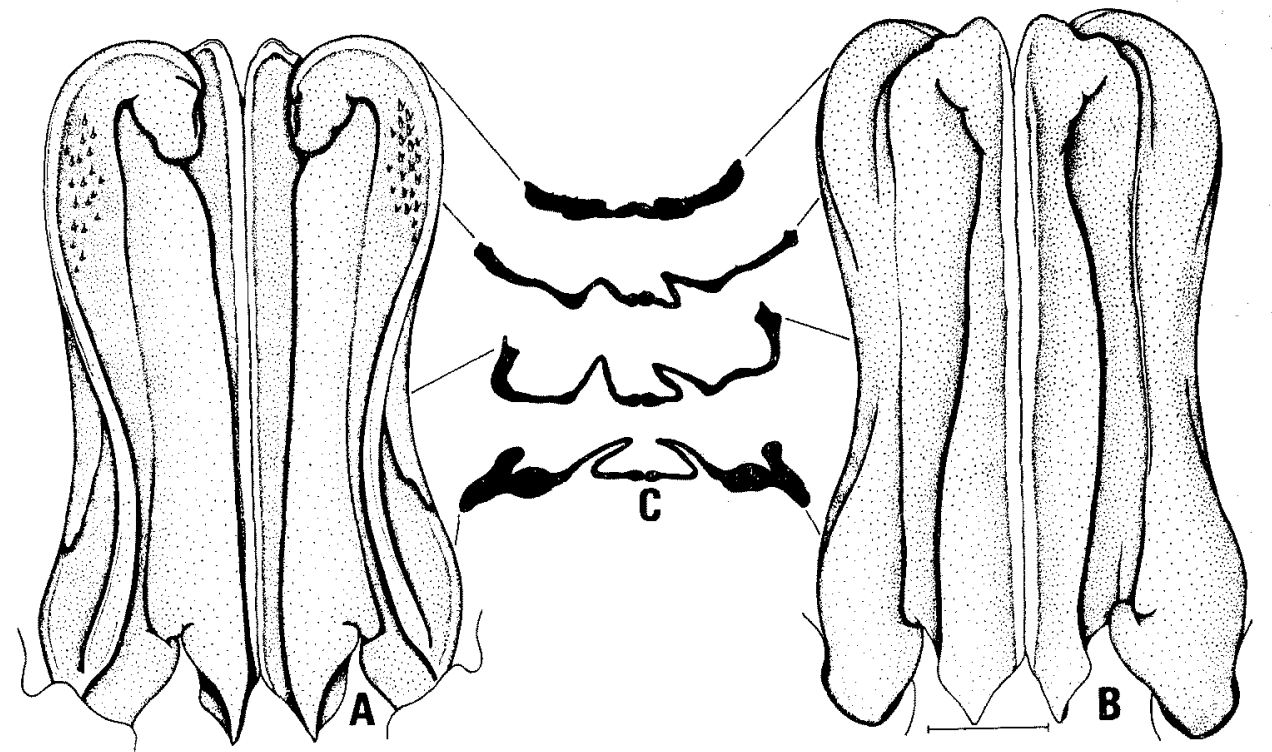

Fig. 4. Ventral (A) and dorsal (B) views of adult petasma (50.8 $\mathrm{mm}$ in CL), and its transections (C). Scale represents $2 \mathrm{~mm}$.

distal tips of the lateral lobes are now very much enlarged, curved inward and overlay the median dorsal lobes more medially. More than 20 anteriorly directed bristles are distributed on the inner surface. The posterior half portion of the petasma lacks bristles (Fig. 3F). There is practically no morphological change in the shape of the petasma hereafter, except that it increases in size with the growth of the animal. The two petasmal components are relatively firmly fused together along the median line. It seems, however, that there is no further increase in the numbers of bristles as the prawn grows. A cross-section of an adult petasma shows that the median lobes are relatively thin and membraneous, while the lateral lobe is stiff, thick and well calcified. Ridges along its margin provide the necessary structural stiffness of the organ. In the posterior section it is clearly visible that the median lobe of each component forms a more or less median tuberculated space which lies ventrally as seen from the normal position on the animal body (Fig. 4).

The relationship between carapace length and petasma length derived from the least square method may be expressed as follows: $Y=-3.5075$ $+0.3025 X,(N=177, r=0.9521)$, where $X$ is the carapace length and $Y$ the petasma length in $\mathrm{mm}$. (Fig. 7).

\section{Development of the Appendix Masculina}

The shape of appendix masculina located on the endopod of the second pleopod, is generally oval or pear-like in shape, and its size and the number of strong spines along the margin increase in accordance with the growth of the prawn.

When the male reaches about $11 \mathrm{~mm}$ in $\mathbf{C L}$, the appendix masculina is merely rod-shaped and devoid of setae or spines (Fig. 5A). When the male reaches about $22 \mathrm{~mm}$ in $\mathrm{CL}$, the appendix masculina becomes stout and armed with 4 or 5 spines (Fig. 5B).

Later development of appendix masculina involves only increment in size and in number of spines as shown in Figs. $5 \mathrm{C}$ to $\mathrm{G}$. The strong spines along its outer and distal margins give the comb like look.

\section{Development of the Thelycum}

The development of the thelycum in this species follows principally the same pattern as established for $P$. indicus by GEORGE and $\mathrm{RAO}^{21}$ and for several other Penaeus species described by KUBO. ${ }^{3 r}$

When the female reaches about $11 \mathrm{~mm}$ in $\mathrm{CL}$, the median plate is discernible as a small elevation between the fourth and the fifth pereiopods on each side (Fig. 6A). The lateral plates are rudimentary but distinct as a pair of elongated triangular plates between the fifth pereiopods on 


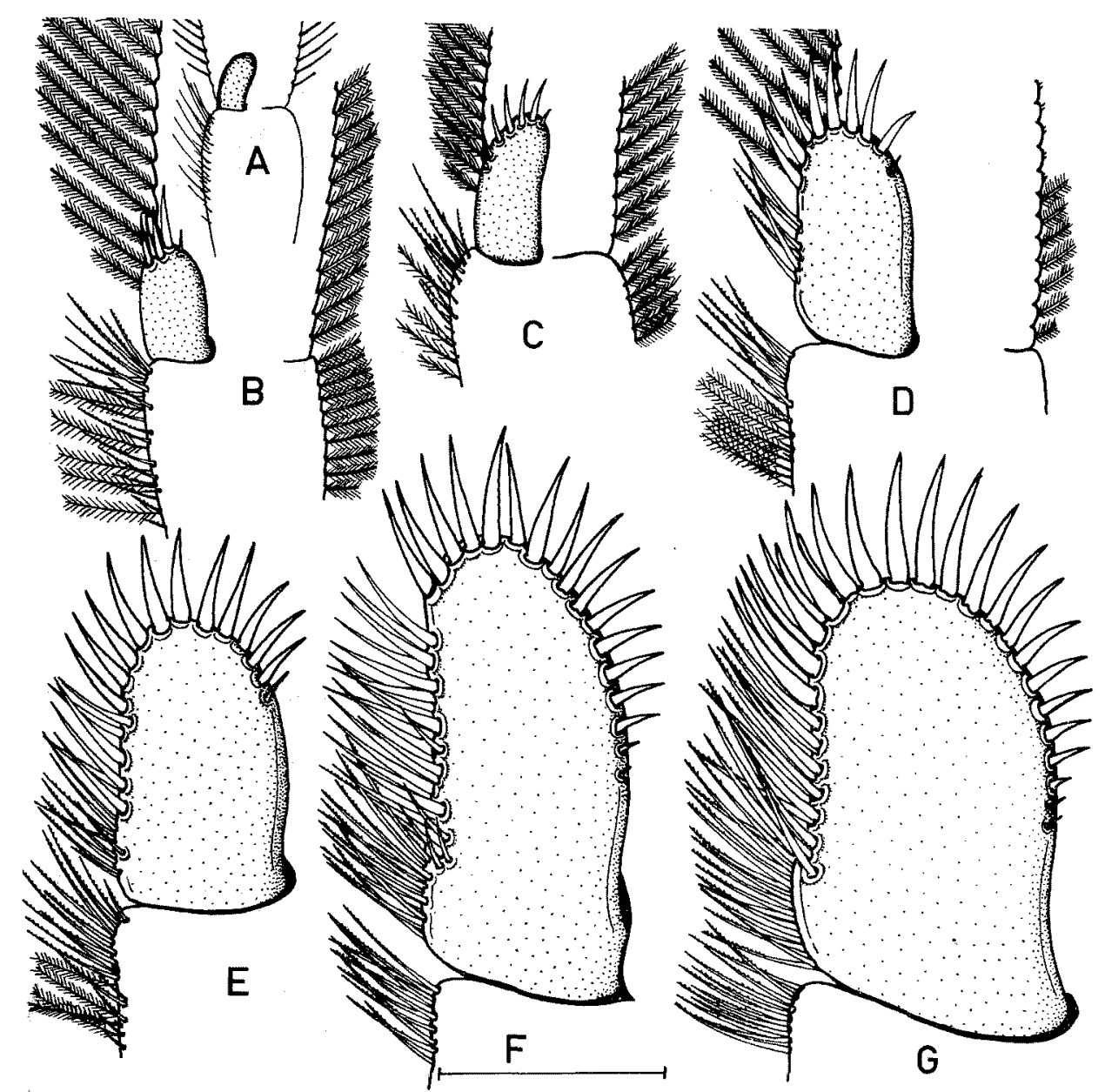

Fig. 5. Development of appendix masculina. A, $11.2 \mathrm{~mm}$ in $\mathrm{CL} ; \mathrm{B}, 21.6 \mathrm{~mm}$ in $\mathrm{CL} ; \mathrm{C}, 23.5 \mathrm{~mm}$ in $\mathrm{CL}$; D, $31.5 \mathrm{~mm}$ in $\mathrm{CL}$; E, $33.2 \mathrm{~mm}$ in $\mathrm{CL} ; \mathrm{F}, 47.0 \mathrm{~mm}$ in $\mathrm{CL}$; and $\mathrm{G}, 50.8 \mathrm{~mm}$ in $\mathrm{CL}$. Scale represents $1 \mathrm{~mm}$.

each side at a size of about $15 \mathrm{~mm}$ in CL (Fig. 6B).

When the female reaches about $22 \mathrm{~mm}$ in $\mathrm{CL}$, the lateral plates on each side are further enlarged and broadened but are still widely spaced in between (Fig. 6C). Further development of the lateral plates is observed in the specimen of about $32 \mathrm{~mm}$ in $\mathrm{CL}$, in which the median plate appears as a raised portion with an elevated round apex. The anterior portion of the lateral plates extends further and begins to overlap the lateral flanges of the median plate. The antero-medial margin of the lateral plate is slightly raised (Fig. 6D).

As the prawn grows to $37 \mathrm{~mm}$ in $\mathrm{CL}$, the lateral plates become broader and extend further anteriorly and medially, completely overlapping the lateral sides of the median plates and leaving only a V-shape slit between them. The lateral plates become crescent shaped with a space at the anterior base. The lateral plates still form a more or less flat surface (Fig. 6E).

When the prawn reaches about $47 \mathrm{~mm}$ in $\mathrm{CL}$, the thelycum assumes the adult form (Fig. 6F). The two lateral plates have thickened considerably (Fig. 6F) with a distinct elevation along the inner lateral margin and occupy almost the entire space in between the sternite of the fifth pair of pereiopods. The lateral plates grow slightly broader posteriorly and meet each other in the median line, while the edges of the plates form an elevated ridge. Externally a $\mathrm{V}$-shaped slit is formed from the median and lateral plates. A concealed hollow space beneath the median plate is formed by the 


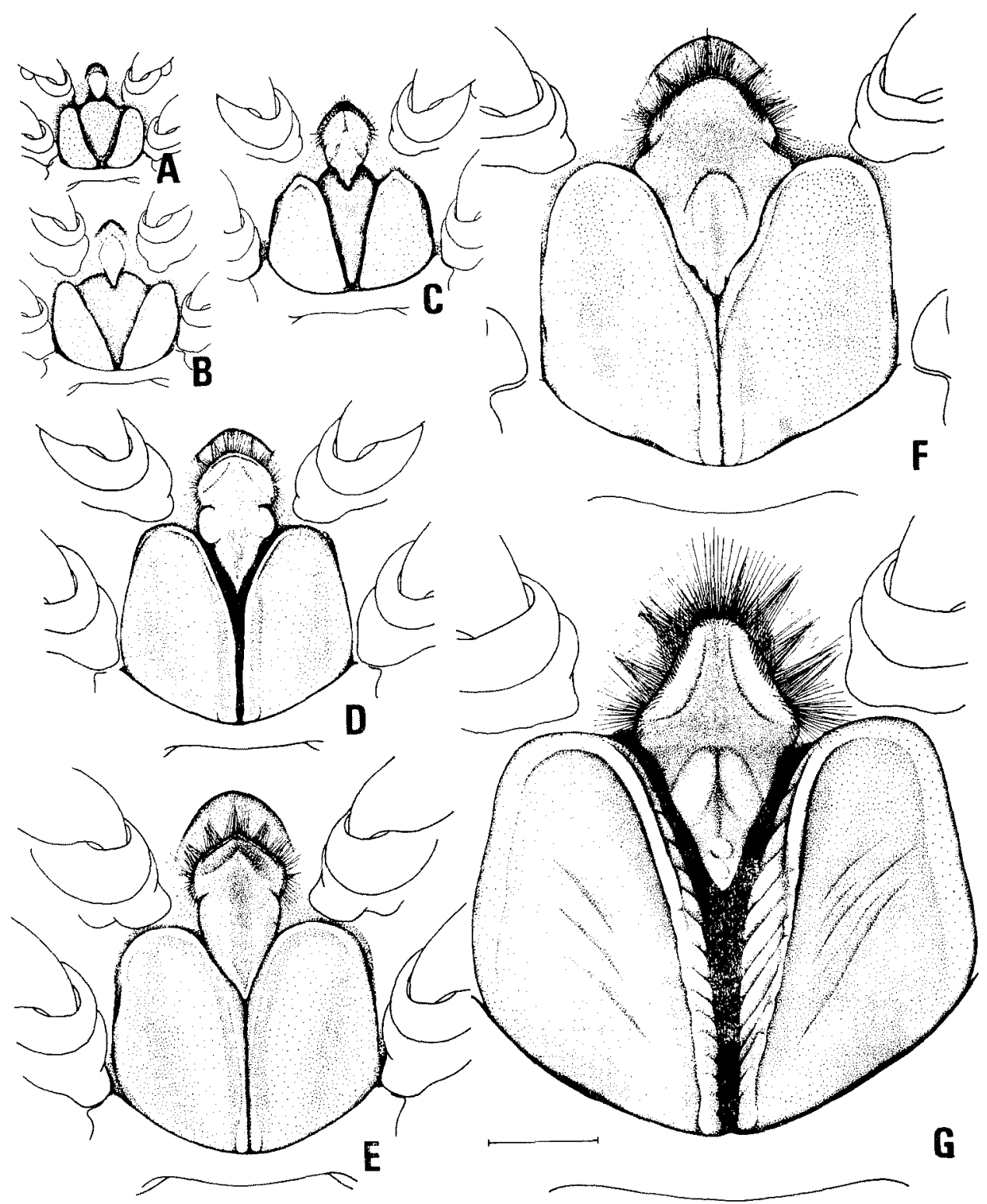

Fig. 6. Development of thelycum. A, $11.7 \mathrm{~mm}$ in $\mathrm{CL} ; \mathrm{B}, 15.2 \mathrm{~mm}$ in $\mathrm{CL} ; \mathrm{C}, 22.4 \mathrm{~mm}$ in $\mathrm{CL}$; D, $31.4 \mathrm{~mm}$ in $\mathrm{CL} ; \mathrm{E}, 36.5 \mathrm{~mm}$ in $\mathrm{CL} ; \mathrm{F}, 46.8 \mathrm{~mm}$ in $\mathrm{CL}$; and $\mathrm{G}, 62.6 \mathrm{~mm}$ in CL. Thelyca $\mathrm{F}$ and $\mathrm{G}$ are inseminated. Scales represents $2 \mathrm{~mm}$.

posterior overhanging of the shelf-like extension, which is visible only upon dissection of the organ.

The relationships between the carapace length and thelycum length, and carapace length and thelycum width for $P$. monodon are expressed as follows:

$Y=-0.8147+0.1878 X$, where $X$ is carapace length and $Y$ thelycum length in $\mathrm{mm}$
$(N=222, r=0.9322)$.

$Y=-0.7565+0.1648 X$, where $X$ is carapace length and $Y$ thelycum width in $\mathrm{mm}$ $(N=223, r=0.9287$ ). (Fig. 7).

\section{Discussion and Summary}

There is a linear relationship between the size 


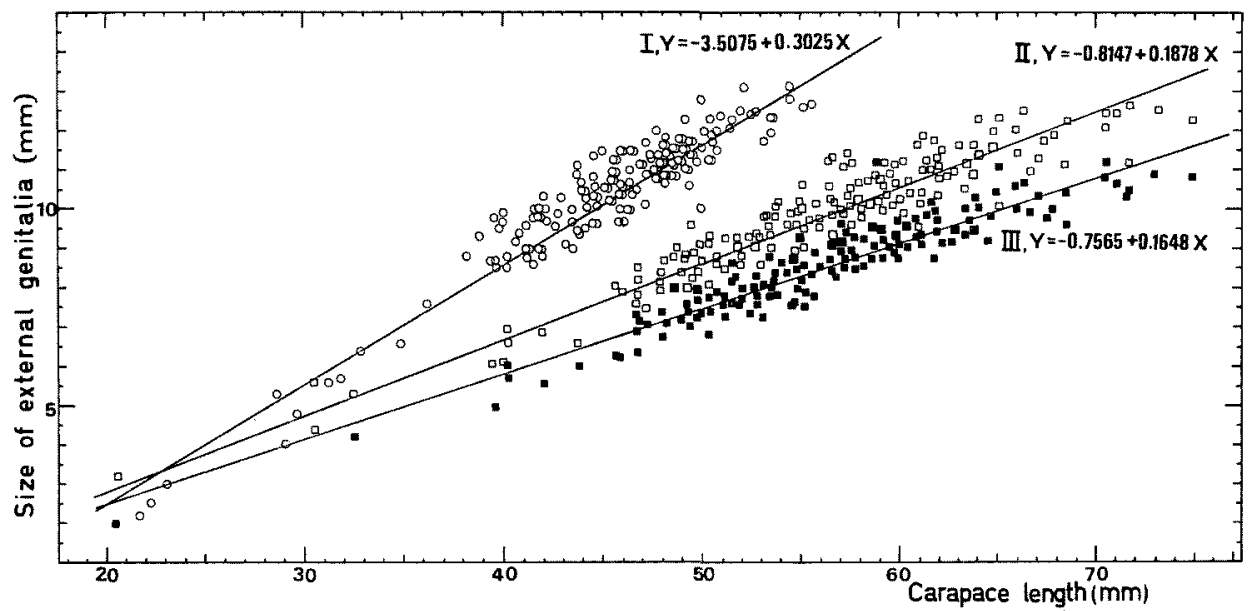

Fig. 7. P. monodon: Relative growth of external genitalia upon carapace length. (I, length of petasma; II, length of thelycum; and III, width of thelycum,)

of the prawn and that of its petasma or thelycum as shown in Fig. 7. When the male reaches approximately $34 \mathrm{~mm}$ in $\mathrm{CL}$, the petasma is structurally complete in the great majority of specimens and is functional as intromittent organ*. In female $\boldsymbol{P}$. monodon, the thelycum is structurally complete in almost all animals of $47 \mathrm{~mm}$ in CL. According to the senior author's own observation, a similar size gap between the sexes mentioned above seems to be common to the other species of the genus Penaeus, but no data has yet been publi-

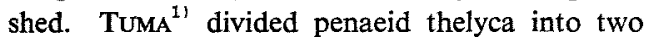
general types, viz. open and closed types. The present study shows that the thelycum of $P$. monodon belongs to the closed type. The appendix masculina of the present material is morphologically quite identical to the classification of these of the genus Penaeus presented by Youoya, ${ }^{71}$ viz. anterior surface of the basal plate without strong elevation, appendage with marginal setae, and appendage longer than broad.

\section{Acknowledgment}

The present authors wish to express their cordial thanks to Dr. Hiroshi KurATA of Nansei Regional Fisheries Research Laboratory, Japan, Dr. Robert
G. WEAR, Victoria University of Wellington, New Zealand and Dr. Tetsushi Senta of Nagasaki University, Japan, for their valuable guidance, suggestions and helpful criticism on the manuscript. Thanks are also extended to Dean Domiciano K. Villaluz and Dr. Noboru Hoshino of the Aquaculture Department of Southeast Asian Fisheries Development Center (SEAFDEC) for the opportunity to conduct this work, Mr. Shigeru KuZaGaI, Mr. Noel Solis and Miss Edna CaligDONG of the SEAFDEC for their kind assistance during the course of the study.

\section{References}

1) D. J. Tuma: Aust. J. Mar. Freshw. Res., 18, 73-88 (1967).

2) M. J. George and P. V. Rao: J. Mar. Biol. Ass. India, 10, 52-70 (1968).

3) I. Kuвo: J. Tokyo Univ. Fish., 36, 1-467 (1949).

4) N. M. Tirmizr: Proc. Zool. Soc. Lond., 131, 231-244 (1958).

5) N. M. TrRmizr: Crustaceana, 15, 194-203 (1968).

6) N. M. TIRMIZI and W. JAVED: Crustaceana, 30, 55-67 (1976).

7) Y. Yokoya: J. Coll. Agr. Tokyo Imp. Univ., 15, 45-68 (1941).

* Мотон, unpublished. 